\title{
Improvements of 6S Look-Up-Table Based Surface Reflectance Employing Minimum Curvature Surface Method
}

\author{
Kyeong-Sang Lee ${ }^{1} \cdot$ Chang Suk Lee ${ }^{2} \cdot$ Minji Seo ${ }^{1} \cdot$ Sungwon Choi ${ }^{1} \cdot$ Noh-Hun Seong ${ }^{1} \cdot$ Donghyun Jin ${ }^{1}$. \\ Jong-Min Yeom ${ }^{3} \cdot$ Kyung-Soo Han ${ }^{1,4}$ (B)
}

Received: 5 July 2019 / Revised: 18 November 2019 / Accepted: 20 November 2019/Published online: 8 January 2020

(C) The Author(s) 2020

\begin{abstract}
We propose a methodology employing an interpolation technique on the Second Simulation of a Satellite Signal (6S) look-up table (LUT) to improve surface reflectance retrieval using Himawari-8/Advanced Himawari Imager (AHI). A minimum curvature surface (MCS) technique was used to refine the 6S LUT, and the solar zenith angle (SZA) and viewing zenith angle (VZA) increments were narrowed by $0.5^{\circ}$. The interpolation processing time was relatively short, about $3172 \mathrm{~s}$ per channel, and the interpolated $x a$ and $x b$ were well represented by the changes in SZA and VZA. An evaluation of the interpolated $x a$ and $x b$ for six cases revealed a relative mean absolute error of less than 5\% for all channels and cases; however, a slight difference was evident for higher values of SZA and VZA. To evaluate the surface reflectance, we compared the surface reflectance derived using 6S LUT with that calculated using 6S only. Application of the interpolated 6S LUT showed a lower relative root mean square error (RRMSE) of $0.65 \%$ to $9.29 \%$ for all channels, than before interpolation. The improvement in surface reflectance measurements increased with the SZA. For a SZA above $75^{\circ}$, the RRMSE improved significantly for all channels (by 11.33-45.1\%). In addition, when the MCS method was applied, the surface reflectance measurements improved without spatial discontinuity and showed good agreement with $6 \mathrm{~S}$ results in a linear profile analyses. Thus, the method proposed can improve LUT based surface reflectance measurements in less time and increase the availability of surface reflectance data based on geostationary satellites.
\end{abstract}

Keywords Atmospheric correction $\cdot 6 \mathrm{~S} \cdot$ Look-up-table $\cdot$ Minimum curvature surface $\cdot$ Surface reflectance

\section{Introduction}

The spectral radiance measured using the satellite sensor is disturbed by absorption and scattering due to gases and aerosols present in the atmosphere on the path of sunlight from the Sun to the surfaces of the Earth and satellite-mounted sensors (Nunes

Responsible Editor: Soon-Il An.

Kyung-Soo Han

kyung-soo.han@pukyong.ac.kr

1 Division of Earth Environmental System Science (Major of Spatial Information Engineering), Pukyong National University, Daeyeon-3 Nam-Gu, Busan 48513, South Korea

2 Environmental Satellite Center, National Institute of Environmental Research, 42, Hwangyeong-ro, Seo-gu, Incheon 22689, South Korea

3 Korea Aerospace Research Institute (KARI), 169-84 Gwahak-ro, Yuseong-gu, Daejeon 305-806, South Korea

4 Department of Spatial Information Engineering, Pukyong National University, Room 602, Busan 48513, South Korea et al. 2008; Hadjimitsis et al. 2010); this phenomenon is referred to as the "atmospheric effect". Absorption of sunlight by the atmosphere attenuates the radiation measured using the sensor. Scattering of sunlight can increase or decrease the radiation received by the sensor, depending on the atmospheric conditions (Proud et al. 2010). The magnitude of atmospheric effect is influenced not only by the amount of atmospheric constituents (i.e., the likelihood that a photon strikes an atmospheric component) but also by the atmospheric path length (i.e., the configuration of the Sun, Earth, and the satellite) (Hilker 2018). In satellite remote sensing, the atmospheric effect is a large source of uncertainty in observing the land surface. Accurate atmospheric correction is an essential pre-processing step to improve satellite image quality for land surface property analyses (Kaufman 1987; JiménezMuñoz et al. 2010).

To eliminate atmospheric effects, previous studies mainly applied the radiative transfer model (RTM), such as the Second Simulation of a Satellite Signal in the Solar Spectrum (6S) and MODerate resolution atmospheric TRANsmission (MODTRAN) (Adler-Golden et al. 1999; 
Kotchenova et al. 2006). The RTM method can be used to characterize the atmospheric effects of surface radiation signals measured using satellite sensors and has several advantages (Liang et al. 2010). It is not limited to a specific region or satellite sensor because it inputs the atmospheric conditions, geometry information, and sensor characteristics of areas where the atmospheric correction is to be performed. In addition, the RTM method is known to be accurate for simulating atmospheric effects in comparison with empirical line method (ELM) and improved dark-object subtraction (IDOS) (Zhou et al. 2011); thus, it is used in various fields, as well as in atmospheric correction of satellite imagery (Zhao et al. 2001; Liang et al. 2012; Zhang et al. 2016; Wu et al. 2017; Yeom et al. 2018). However, the RTM method has a disadvantage in that it takes a long time to perform atmospheric correction over a wide area, such as that of satellite images, because the calculation process is complex and the processing times are long. To overcome this issue, several studies have applied the look-uptable (LUT) method, which is an array-based method that replaces run-time calculations with simple array indexing (Liang et al. 2001; Lyapustin et al. 2011; Dorji and Fearns 2018). In constructing the LUT, the increment and range of input parameters directly affect the accuracy of atmospheric correction and computational efficiency (Qu et al. 2014).

The 6S LUT is used for the operational atmospheric correction algorithm of the Geostationary Operational Environmental Satellite-R series (GOES-R) and the Visual Infrared Imaging Radiometer Suite (VIIRS) (Liang et al. 2010; Franch et al. 2016). When constructing these LUTs, the increments for the solar zenith angle (SZA) and viewing zenith angle (VZA) were set to $4-5^{\circ}$, to optimize atmospheric correction accuracy and computational efficiency. At a higher SZA $\left(>70^{\circ}\right)$, the changes in atmospheric effects with variation in the angular measures (SZA and VZA) introduce significant error to surface reflectance measurements (Fraser et al. 1992). This is important not only in high-latitude regions where satellite observations are available at high SZA but also in terms of the availability of data measured with geostationary satellite sensors such as the Advanced Himawari Imager (AHI) on board the Himawari-8 satellite. With geostationary satellites in particular, observations are made at high SZA on a continuous basis; accurate surface reflectance data are required in terms of data utilization (Ruddick et al. 2014; Lee et al. 2015). To reduce the error at a high SZA, the interval of the input parameter should be set narrow in the LUT construction; however, this approach is limited by the long processing times.

In this study, we describe a method to refine the 6S LUT with short processing times that improve the quality of surface reflectance measurements over a wide SZA range, based on the minimum curvature surface (MCS) method. The MCS method is a common gridding technique used to construct a smooth surface from irregularly spaced data (Kaven et al. 2009; Rabah and Kaloop 2013). Computer implementation of the MCS method with a tension parameter to minimize extraneous inflection points was demonstrated by Smith and Wessel (1990); notably, the inclusion of a tension parameter did not introduce additional computational complexity to the MCS method. The MCS method is also commonly used for data interpolation in remote sensing fields (Patenaude et al. 2004; Nefeslioglu et al. 2012; Dietz et al. 2017; Gittings et al. 2017). Here, the MCS method was used to refine the 6S LUT to improve the surface reflectance quality for application to the Himawari-8/AHI that is a geostationary satellite observing the Asia-Oceania region over a wide range of SZAs and VZAs. Our results were compared to surface reflectance values calculated using $6 \mathrm{~S}$ input values at the given observation time.

The remainder of this paper is organized as follows. Section 2 describes the data used in this research. The methodology for interpolating 6S LUT data is explained in Section 3. In Section 4, we present qualitative and quantitative assessments of our results, compared to surface reflectance calculations based on non-interpolated LUT and 6S. Our findings are summarized in Section 5.

\section{Data}

Himawari- 8 is a next-generation geostationary meteorological satellite operated by the Japan Meteorological Agency (JMA) that was launched successfully on August 7, 2014 and began operation on July 7, 2015 (Yumimoto et al. 2016). The AHI on board the Himawari- 8 satellite employs 16 channels from 0.47 to $13.3 \mu \mathrm{m}$ (Choi and Suh 2018). The AHI instrument monitors a full disk area that includes Asia and Oceania; these areas are composed of various climatic zones and land cover types, ranging from broadleaf evergreen forests to barren lands. AHI images are acquired every $10 \mathrm{~min}$, providing one of the highest temporal resolutions. Therefore, AHI provides multiple satellite images every day, which is a considerable advantage in areas where cloud cover is frequent, such as during Asia's summer season. AHI is suitable for the current study, because it acquires data on various atmospheric conditions, such as the water vapor content, ozone content, and aerosol optical depth (AOD), as well as measurements of the solar zenith and azimuth angles as the Earth rotates. For atmospheric correction, we used top of the atmosphere (TOA) radiance data from five shortwave channels centered at 0.47 , $0.51,0.67,0.86$, and $1.61 \mu \mathrm{m}$, respectively (Table 1 ). The TOA radiance data used in this study has the same temporal resolution but different spatial resolution. The spatial resolution of two visible channels (channel 1 and 2) and one nearinfrared channel (channel 4) is $1 \mathrm{~km}$. On the other hand, one visible channel (channel 3) and a SWIR channel (channel 5) have spatial resolutions of $0.5 \mathrm{~km}$ and $2 \mathrm{~km}$, respectively. The TOA radiance data from the five shortwave channels were 
Table 1 Characteristics of shortwave channels from Himawari-8/AHI used in this study

\begin{tabular}{llll}
\hline $\begin{array}{l}\text { Channel } \\
\text { wavelength }(\mu \mathrm{m})\end{array}$ & $\begin{array}{l}\text { Sentral } \\
\text { sub-satellite point }(\mathrm{km})\end{array}$ & $\begin{array}{l}\text { Time cycle for } \\
\text { full disk }(\mathrm{min})\end{array}$ \\
\hline 1 & 0.47 & 1 & 10 \\
2 & 0.51 & 1 & 10 \\
3 & 0.64 & 0.5 & 10 \\
4 & 0.85 & 1 & 10 \\
5 & 1.61 & 2 & 10 \\
\hline
\end{tabular}

resampled at $2 \mathrm{~km}$ resolution. The spectral response function (SRF) for these channels, provided by the JMA, was also used for the 6S RTM simulations.

We performed atmospheric corrections of five shortwave channels only for cloud-free land surfaces. For the removal of cloud cover and water bodies, we used cloud mask and land/sea mask data provided by the National Metrological Satellite Center (NMSC). In addition, total precipitable water (TPW), total column ozone (TCO), and AOD data provided by the NMSC were used to characterize the atmospheric conditions at the AHI observation time; these data were generated by applying the GK2A/AMI algorithm to Himawari-8/AHI. These data were used from 1 July to 7 August 2017 with $1 \mathrm{~h}$ intervals.

The cloud mask used in this research was output from the Geokompsat-2A (GK-2A)/Advanced Meteorological Image (AMI) cloud mask algorithm applied to Himawari-8/AHI. The GK-2A cloud mask algorithm was developed based on the threshold method considering channel characteristics according to the presence of the clouds and is currently used for operational purposes. Each pixel was classified by one of cloudy, probably cloudy and clear through threshold tests including single channel test, two-channel tests, spatial uniformity test and inversion layer correction (NMSC 2019). Its accuracy is $92 \%$ and $13 \%$ for POD and FAR, respectively, compared to the Moderate Resolution Imaging Spectroradiometer (MODIS) cloud mask product (MYD35). The land/sea mask data was generated using MODIS yearly land cover data (MCD12Q1).

\section{Methods}

Figure 1 shows the research flow chart for this study. We first constructed two LUTs (a non-interpolated and an interpolated 6S LUT) to remove atmospheric effects from AHI observation data. A non-interpolated 6S LUT was constructed for each AHI shortwave channel, through 6S RTM simulations of various input condition combinations. The interpolated 6S LUT was created by refining the interval of the input conditions in the non-interpolated 6S LUT, using the MCS method. The construction of the 6S LUT is discussed in more detail in the sections to follow. Then atmospheric correction coefficients of the most similar conditions to those of the present observation conditions were selected from two 6S LUTs. The surface reflectance values for the five shortwave channels were estimated using a simple equation provided by $6 \mathrm{~S}$. The surface reflectance is calculated only for the pixels classified as "confident clear" in the cloud mask product. To verify the improvement in the surface reflectance measurements, according to $6 \mathrm{~S}$ LUT interpolation, the top-of-canopy surface reflectance calculated using the interpolated 6S LUT based on the MCS method (TOC reflectance ${ }_{\mathrm{MCS}}$ ) and the TOC surface reflectance calculated using the non-interpolated 6S LUT (TOC reflectance $_{\text {LUT }}$ ) were compared to the TOC surface reflectance calculated directly using $6 \mathrm{~S}$ (TOC reflectance $_{6 \mathrm{~S}}$ ).

\subsection{S RTM}

The 6S RTM was used to correct for atmospheric effects in TOA radiance measurements observed by $\mathrm{AHI}$. The $6 \mathrm{~S}$ was developed by Vermote et al. (1997) as an improved version of the 5S. A vector version of $6 \mathrm{~S}(6 \mathrm{SV})$ was introduced in 2005 and is based on successive orders of scattering approximations. In addition, $6 \mathrm{SV}$ is capable of accounting for radiation polarization based on calculations of the four Stokes vector components (Vermote et al. 2006). The 6SV RTM calculates the scattering and absorption effects of the atmospheric components such as water vapor, ozone, and aerosol for a broad range of atmospheric, aerosol, spectral, and geometrical conditions. This calculation is performed by dividing the bandwidth of the channel by $2.5 \mathrm{~nm}$. Kotchenova et al. (2008) evaluated the accuracy of four RTMs, including 6SV, MODTRAN, RT3 (radiative transfer), and SHARM (spherical harmonics), via a comparison with Coulson's tabulated values and Bréon's Monte Carlo code, both well-known benchmarks. 6SV shows higher simulation accuracy than MODTRAN, RT3 and SHARM with less than $1 \%$ error under several atmospheric condition scenarios. Due to the high accuracy of 6SV, it is used in radiometric calibration, retrieval of AOD, and surface albedo studies, as well as for atmospheric correction (Zhang et al. 2016; Wu et al. 2017; Yeom et al. 2018).

6SV calculates the surface reflectance based on the following:

$$
\begin{aligned}
\rho_{T O A}\left(\theta_{s}, \theta_{v}, \phi\right)= & T g\left(\theta_{s}, \theta_{v}\right) \\
& \times\left[\rho_{R+A}+T^{\downarrow}\left(\theta_{s}\right) T^{\uparrow}\left(\theta_{v}\right) \frac{\rho_{s}}{1-S \rho_{s}}\right],
\end{aligned}
$$

with

$\rho_{s}=\frac{\frac{\rho_{T O A}\left(\theta_{s}, \theta_{v}, \phi\right)}{T_{g}\left(\theta_{s}, \theta_{v}\right)}-\rho_{R+A}}{T^{\downarrow}\left(\theta_{s}\right) T^{\uparrow}\left(\theta_{v}\right)}$,

where $\rho_{T O A}$ is the TOA reflectance. $\theta_{s}, \theta_{v}$ and $\phi$ represent the 
Fig. 1 Flow chart of the procedures for retrieval and comparison of surface reflectance. RTM: radiative transfer model; LUT: look-up table; TOA: top of the atmosphere; SZA: solar zenith angle; VZA: viewing zenith angle; RAA: relative azimuth angle; TPW: total precipitable water; TCO: total column ozone; AOD: aerosol optical depth; MCS: minimum curvature surface

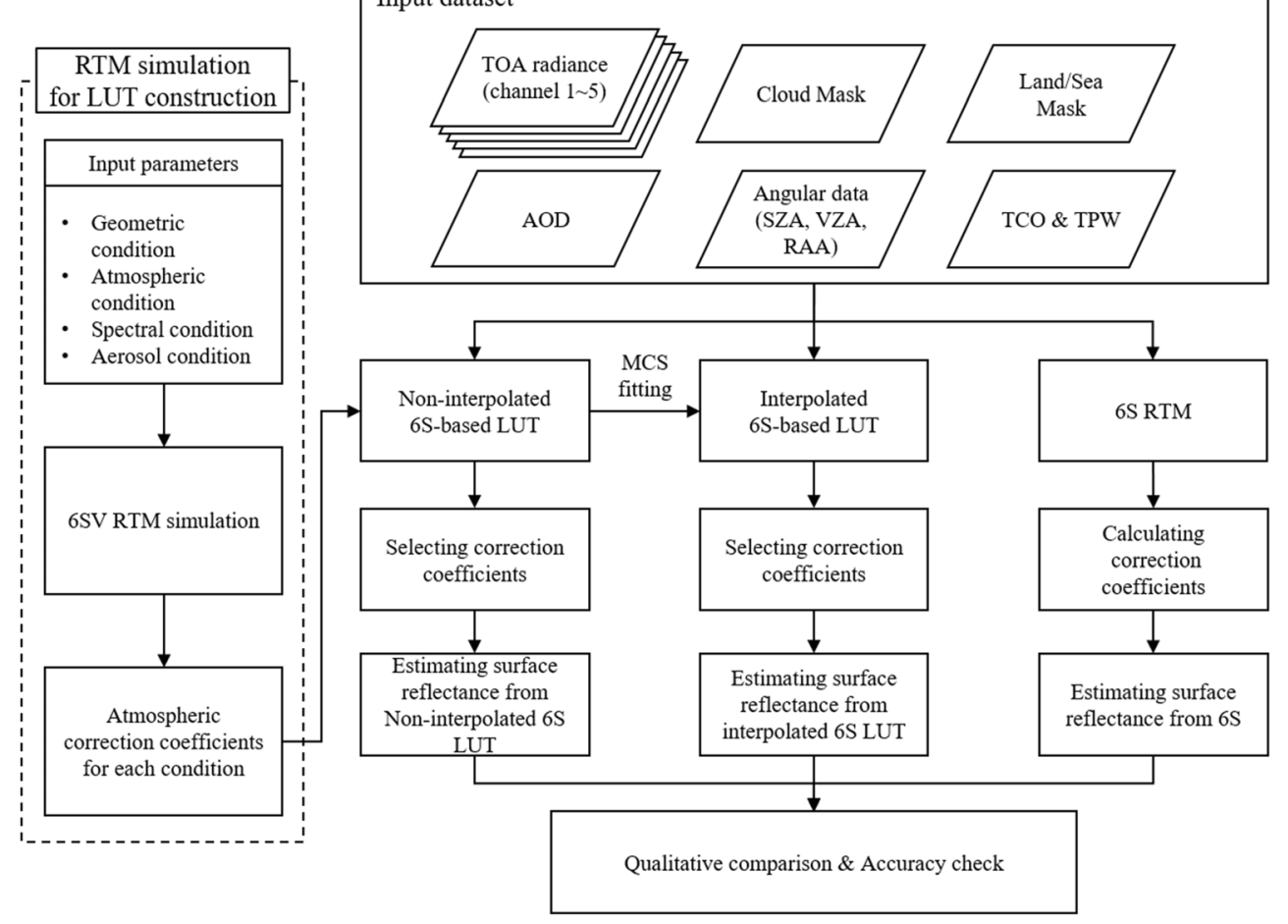

SZA, VZA, and relative azimuth angle (RAA), respectively. $T_{g}$ represents the total gaseous transmission of $\mathrm{H}_{2} \mathrm{O}, \mathrm{CO}_{2}, \mathrm{O}_{2}$ and $\mathrm{O}_{3} . S$ denote the spherical albedo of the atmosphere. $\rho_{R+A}$ represents the total reflectance of the molecule and aerosol scattering. $T^{\downarrow}\left(\theta_{s}\right)$ and $T^{\uparrow}\left(\theta_{\mathrm{v}}\right)$ represent the value of the total transmission of the atmosphere along the radiation path between the Sun and the land surface and the satellite and land surface, respectively. Finally, $\rho_{s}$ is equation of transfer for a Lambertian homogeneous target of reflectance. $6 \mathrm{SV}$ provides three correction coefficients $(x a, x b$, and $x c)$ as output for the input condition to remove atmospheric effects. The surface reflectance can be calculated from TOA radiance from Eq. (3) using the three atmospheric correction coefficients.

$\rho_{T O C}=\frac{x a \cdot L-x b}{1+x c(x a \cdot L-x b)}$

In the above equation, $\rho_{T O C}$ denotes the calculated surface reflectance and $L$ represents the TOA radiance (units: $\mathrm{W} \mathrm{m}^{-}$

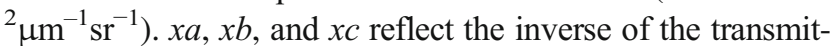
tance, the scattering term of the atmosphere, and spherical albedo (atmospheric reflectance for isotropic light), respectively.

\subsection{Pre-Construction of the 6S LUT}

There are two methods for performing atmospheric correction using $6 \mathrm{~S}$. The first method is to perform atmospheric correction by calculating the atmospheric effects using $6 \mathrm{~S}$ directly; the other approach is to simulate $6 \mathrm{SV}$ for various possible input conditions in advance and to store the results in the form of an LUT. The method of directly performing atmospheric correction using $6 \mathrm{~S}$ is not suitable for processing a large amount of data, as similar calculations are repeated and the processing time is long. Therefore, we used the LUT method to avoid duplicate calculation processes and to accelerate the processing time. Table 2 shows the range and interval of input parameters used in this study for pre-construction of the 6S LUT; notably these values are important factors in atmospheric correction (Proud et al. 2010). The SZA and VZA had a range from $0^{\circ}$ to $80^{\circ}$ and varied in $5^{\circ}$ increments. The RAA had a range of $0^{\circ}$ to $180^{\circ}$, with a $10^{\circ}$ increment. For the atmospheric conditions, the ranges of TPW and TCO were set to $0-5 \mathrm{~g} \mathrm{~cm}^{-2}$ and $0.25-0.35 \mathrm{~atm}-\mathrm{cm}$, with intervals of $1 \mathrm{~g} \mathrm{~cm}^{-2}$ and $0.05 \mathrm{~atm}-\mathrm{cm}$, respectively, with reference to Lee et al. (2015). The input conditions for AOD consisted of 12 values an irregular interval, with reference to the values used by Liang et al. (2010). The three aerosol types were used: 'continental,' 'background desert,' and 'maritime'. We used the SRF of the AHI provided by the JMA to consider the spectral condition. The $6 \mathrm{SV}$ was performed for all combinations of each condition shown in Table 2. The three atmospheric correction coefficients $(x a, x b$, and $x c)$ provided by $6 \mathrm{~S}$ were stored in a LUT with a seven-dimensional structure answering input conditions (SZA, VZA, RAA, TPW, TCO, AOD, and aerosol type). To narrow the interval, we applied an MCS fitting method to the 6S LUT and narrowed the intervals for SZA and VZA conditions, as the volume of the constructed LUT becomes too large 
Table 2 Input parameters for preconstructing 6S LUT

\begin{tabular}{|c|c|c|c|c|}
\hline Parameter & & From & To & Increment \\
\hline \multirow[t]{3}{*}{ Geometric condition } & SZA $\left({ }^{\circ}\right)$ & 0 & 80 & 5 \\
\hline & $\operatorname{VZA}\left({ }^{\circ}\right)$ & 0 & 80 & 5 \\
\hline & $\operatorname{RAA}\left({ }^{\circ}\right)$ & 0 & 180 & 10 \\
\hline \multirow[t]{2}{*}{ Atmospheric condition } & TPW $\left(\mathrm{g} \mathrm{cm}^{-2}\right)$ & 0 & 5 & 1 \\
\hline & TCO (atm-cm) & 0.25 & 0.35 & 0.05 \\
\hline \multirow[t]{2}{*}{ Aerosol model } & AOD & \multicolumn{3}{|c|}{$0.01,0.050 .1,0.15,0.2,0.3,0.4,0.6,0.8,1.0,1.5,2.0$} \\
\hline & Aerosol type & \multicolumn{3}{|c|}{ Continental, background desert, maritime } \\
\hline Spectral condition & & \multicolumn{3}{|c|}{ SRF of each channel (every $2.5 \mathrm{~nm}$ ) } \\
\hline
\end{tabular}

LUT: look-up table, SZA: solar zenith angle, VZA: viewing zenith angle, RAA: relative azimuth angle, $T P W$ : total precipitable water, $T C O$ : total column ozone, $A O D$ : aerosol optical depth, $S R F$ : spectral response function when the interval is refined for all input conditions. Among the three correction coefficients, $x c$ did not change with SZA and VZA. Therefore, interpolation using MCS was not performed for $x c$. For the remaining correction factors $x a$ and $x b$, we applied the MCS fitting method using an Interactive Data Language (IDL) routine to the $6 \mathrm{~S}$ LUT to narrow the increment of SZA and VZA from $5^{\circ}$ to $0.5^{\circ}$ over the $80^{\circ}$ range, taking into account the processing time and capacity. The MCS method is usually applied to define gradual variation in the surface and is equally applicable to equally spaced, line-oriented data, as a fast interpolation approach (Rufo et al. 2018). This method fits the linear elastic plate using data values that minimize the amount of bending to produce an optimal smooth surface (Grgić et al. 2015).

\subsection{Accuracy Assessment}

To evaluate the accuracy of surface reflectance according to the interpolation of the 6S LUT, we used three quantitative indicators, namely, mean absolute error (MAE), root mean square error (RMSE), and relative RMSE (RRMSE). The MAE is frequently used to evaluate accuracy and is derived from the absolute value of the difference between the
Non-interpolated xa
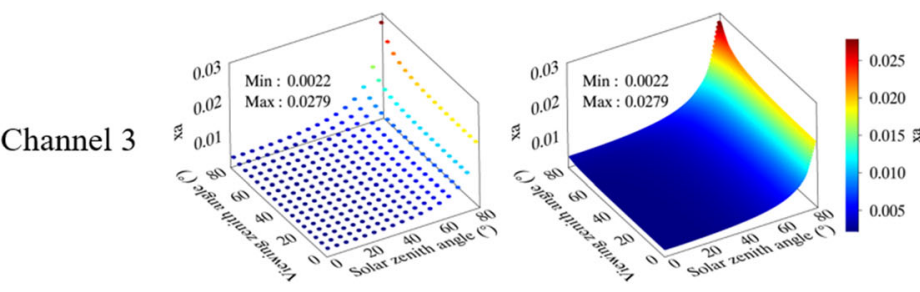

Interpolated xa
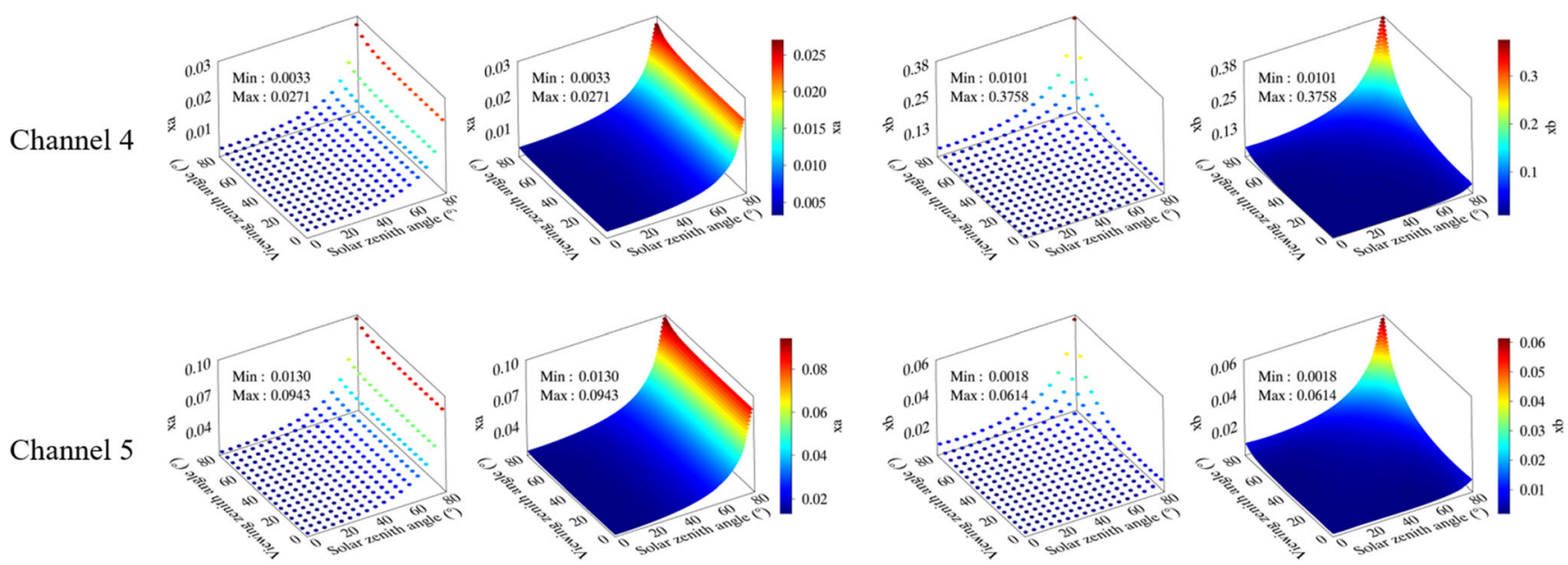

Fig. 2 Atmospheric correction factor according to SZA and VZA for channel 3 (top), 4 (middle) and 5 (bottom). The first and third columns represent the non-interpolated $x a$ and $x b$ respectively, and the second and fourth columns represent the interpolated $x a$ and $x b$, respectively 
Table 3 Relative azimuth angle (RAA) and aerosol optical depth (AOD) values of six cases for quantitative evaluation of atmospheric correction coefficients

\begin{tabular}{lll}
\hline Case & RAA $\left(^{\circ}\right)$ & AOD \\
\hline 1 & 0 & 0.01 \\
2 & 0 & 0.80 \\
3 & 90 & 0.01 \\
4 & 90 & 0.80 \\
5 & 180 & 0.01 \\
6 & 180 & 0.80 \\
\hline
\end{tabular}

estimated and reference values (Willmott and Matsuura 2005). The RMSE is a standard statistical metric for measuring accuracy (Chai and Draxler 2014) and is used to compare the differences between two values in various studies. The RRMSE is calculated by normalizing the RMSE using the mean value of the reference data and is expressed as a percentage (Despotovic et al. 2016). These indicators can be calculated by following equations:

$M A E=\frac{\sum_{i=1}^{N}\left|x_{i}-y_{i}\right|}{N}$,

$R M S E=\sqrt{\frac{\sum_{i=1}^{N}\left(x_{i}-y_{i}\right)^{2}}{N}}$,

$R R M S E=\frac{R M S E}{x} \times 100 \%$

In the above equations, $x$ represents the true value, in this case, the surface reflectance calculated directly from $6 \mathrm{~S} ; y$ is the estimated value, here, the surface reflectance derived by non-interpolated and interpolated 6S LUTs. $N$ and $\bar{x}$ represent the number of observations and the mean of $x$, respectively.

\section{Results}

\subsection{Evaluation of Interpolated 6S LUT}

Figure 2 shows the $x a$ and $x b$ values of the interpolated 6S LUT and the non-interpolated 6S LUT, depending on SZA and VZA, for one combination of input parameters (relative azimuth angle, RAA: $30^{\circ}$; AOD: 0.1; TPW: $3 \mathrm{~g} / \mathrm{cm}^{2}$; TCO: $0.3 \mathrm{~atm}-\mathrm{cm}$, and aerosol type: continental). The non-interpolated 6S LUT constructed in this study well expressed the changes in the atmospheric correction coefficients with changes in the SZA and VZA. In the case of $x a$, the change in its value was more strongly affected by changes in the SZA than the VZA. In the case of $x b$, the effects of changes in the SZA and VZA on the change in $x b$ were similar. When the SZA and VZA are relatively low, the rates of change in $x a$ and $x b$ are small in response to changes in the SZA and VZA. However, at higher SZA and VZA $\left(>70^{\circ}\right)$, the atmospheric correction coefficients change significantly with changes in the zenith angles. As mentioned, this tendency is an error factor in the atmospheric correction using the LUT. The interpolated 6S LUT shows a trend similar to that of the noninterpolated 6S LUT with the same minimum and maximum values. Particularly, $x a$ and $x b$ of the 6S LUT interpolated by the MCS fitting method well expressed the peak value at high SZA and VZA. We measured the elapsed time for interpolation of 6S LUT by the MCS method using a personal computer (Intel Core i5-9400F CPU; 16 GB memory). After constructing the $6 \mathrm{~S}$ (a)

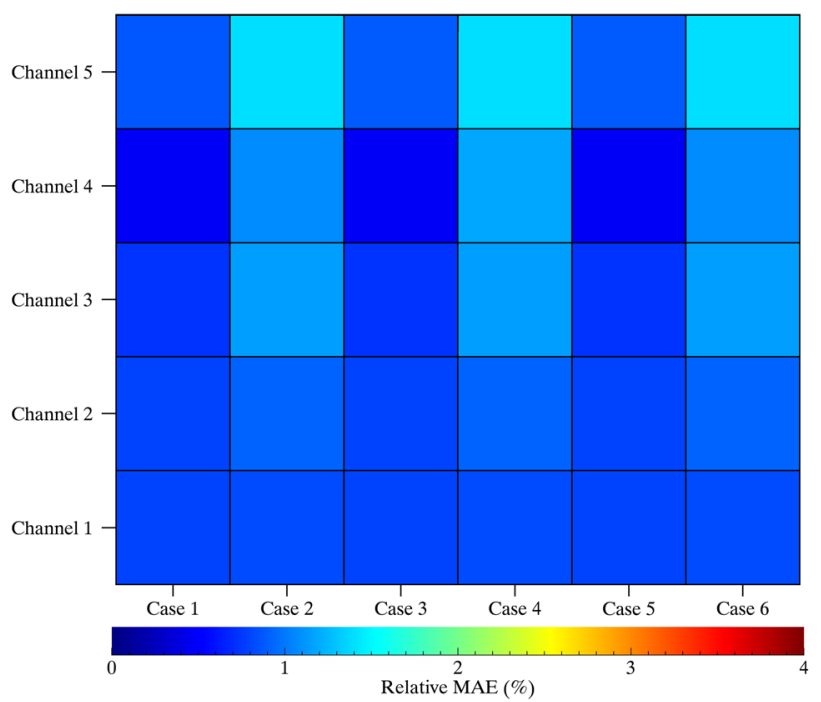

(b)

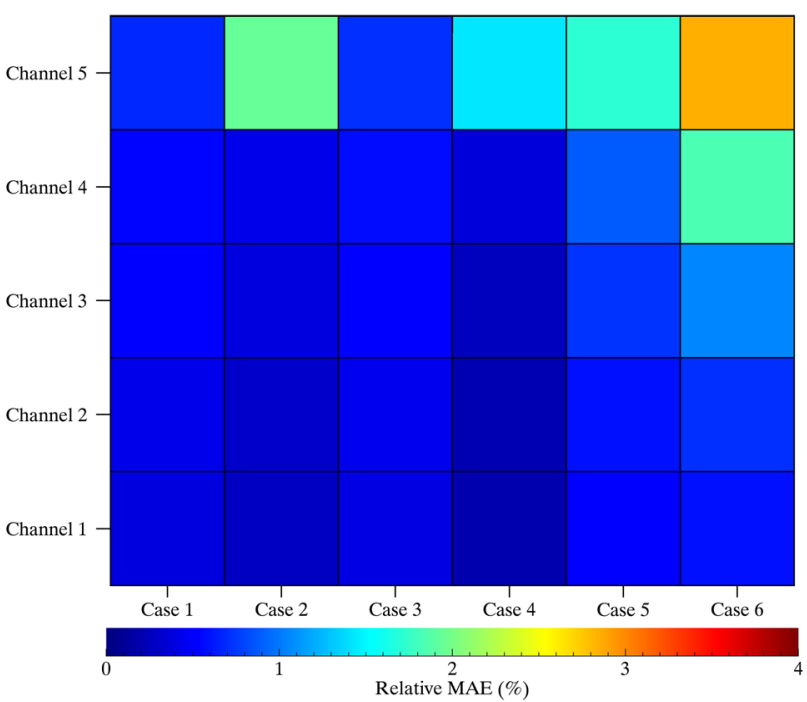

Fig. 3 Relative mean absolute error (MAE) of (a) xa and (b) xb for each channel and each case 
Fig. 4 Histogram of (a) SZA (Solar Zenith Angle) and (b) VZA (Viewing Zenith Angle) of sampled pixels for quantitative comparison (a)

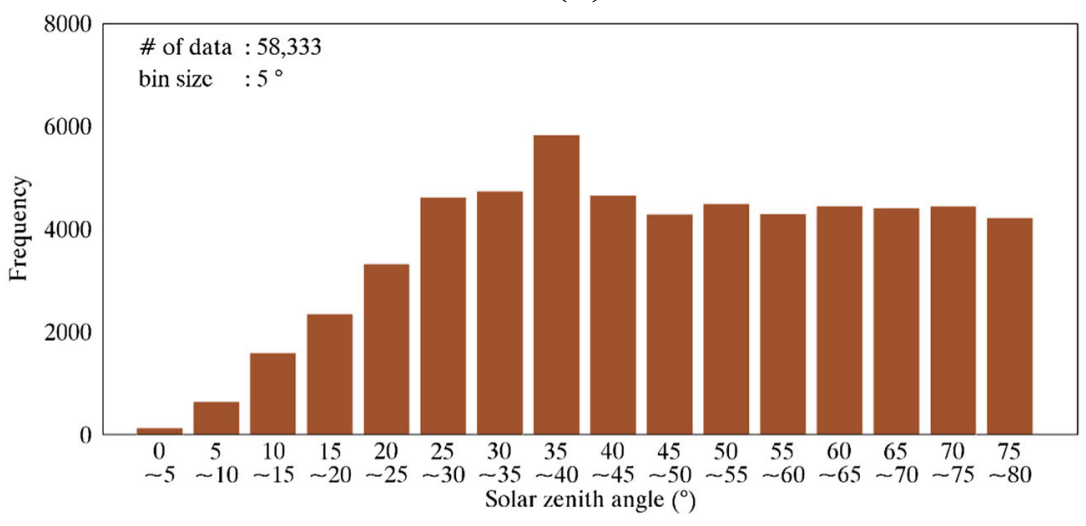

(b)

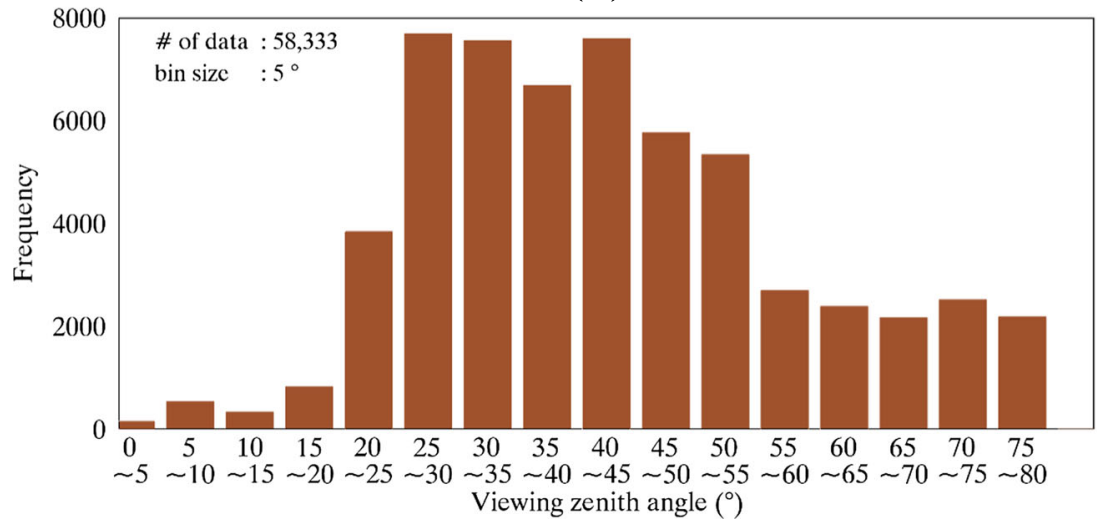

LUT, the time taken to construct the interpolated LUT by the MCS method was about $3172.18 \mathrm{~s}$ per channel. This is a much shorter time than that required when using $6 \mathrm{~S}$ directly to construct an LUT with narrow intervals of SZA and VZA $\left(0.5^{\circ}\right)$.

For quantitative evaluation of the interpolated 6S LUT, the atmospheric correction coefficients $(x a$ and $x b)$ from the

Table 4 Validation result of TOC reflectance LuT $_{\text {and TOC }}$ reflectance $_{\mathrm{MCS}}$ compared to TOC reflectance ${ }_{6 \mathrm{~S}}$

\begin{tabular}{|c|c|c|c|c|c|c|}
\hline \multirow[t]{2}{*}{ Channel } & \multicolumn{3}{|c|}{ TOC reflectance LUT } & \multicolumn{3}{|c|}{$\mathrm{TOC}_{\text {reflectance }} \mathrm{MCS}$} \\
\hline & MAE & RMSE & $\begin{array}{l}\text { RRMSE } \\
(\%)\end{array}$ & MAE & RMSE & $\begin{array}{l}\text { RRMSE } \\
(\%)\end{array}$ \\
\hline 1 & 0.0048 & 0.0065 & 17.51 & 0.0026 & 0.0036 & 9.29 \\
\hline 2 & 0.0040 & 0.0055 & 12.18 & 0.0023 & 0.0032 & 6.95 \\
\hline 3 & 0.0031 & 0.0043 & 4.58 & 0.0014 & 0.0020 & 2.02 \\
\hline 4 & 0.0050 & 0.0062 & 2.10 & 0.0014 & 0.0019 & 0.65 \\
\hline 5 & 0.0036 & 0.0048 & 2.21 & 0.0014 & 0.0020 & 0.78 \\
\hline
\end{tabular}

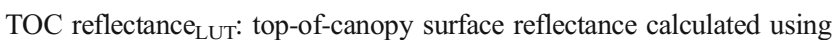
the non-interpolated 6S LUT; TOC reflectance ${ }_{\mathrm{MCS}}$ : TOC surface reflectance calculated using the interpolated 6S LUT, based on the minimum curvature surface method; TOC reflectance ${ }_{65}$ : TOC reflectance calculated directly using 6S; MAE: mean absolute error; RMSE: root mean square error; RRMSE: relative RMSE; MCS: minimum curvature surface interpolated 6S LUT were compared to the atmospheric correction coefficients calculated directly by $6 \mathrm{~S}$, as a reference for the six cases of the combination of the three RAA conditions $\left(0,90,180^{\circ}\right)$ and the two AOD conditions $(0.01,0.8)$. Table 3 shows the RAA and AOD conditions for each case. TPW and TCO were fixed at $1 \mathrm{~g} \mathrm{~cm}^{-2}$ and $0.3 \mathrm{~atm}-\mathrm{cm}$, respectively; these parameters have relatively little influence over atmospheric correction in the shortwave region, except for specific wavelengths, such as $1380 \mathrm{~nm}$, that are absorbed strongly by water vapor (Meyer et al. 2016). Figure 3 shows the relative MAEs of $x a$ and $x b$ for each channel and case. The relative MAE is the value of the MAE divided by the average value of the reference data. In the case of $x a$, the interpolated $x a$ through the MCS method showed good agreement with the $x a$ calculated directly using $6 \mathrm{~S}$ in all cases and for all channels, with a relative MAE of less than $2 \%$. The minimum value of the relative MAE was $0.478 \%$ in case 1 of channel 4 , and the maximum value was $1.4 \%$ in case 4 of channel 5 . Although the differences were small under most SZA and VZA conditions, the difference in $x a$ became increasingly large when the SZA exceeded $75^{\circ}$, up to $0.014(8.15 \%)$ in case 6 of channel 5. For SZA above $75^{\circ}$, the $x a$ increased sharply with the SZA. The interpolation performance of the MCS method becomes degraded when the data change over short intervals (Rufo 
(a)

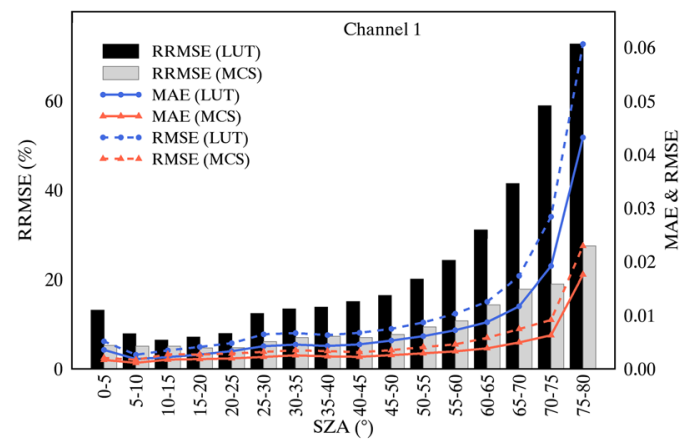

(c)

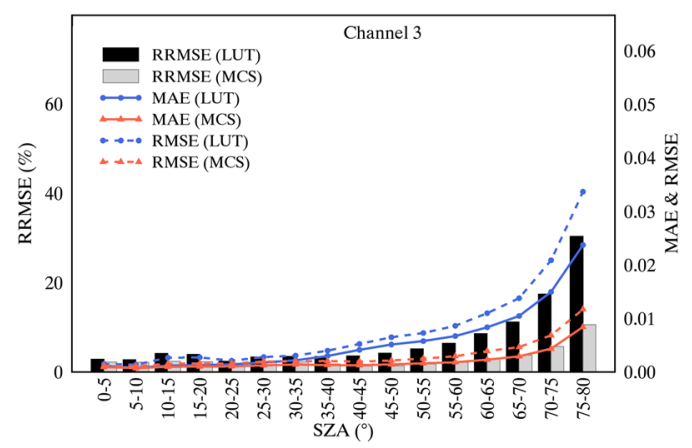

(b)

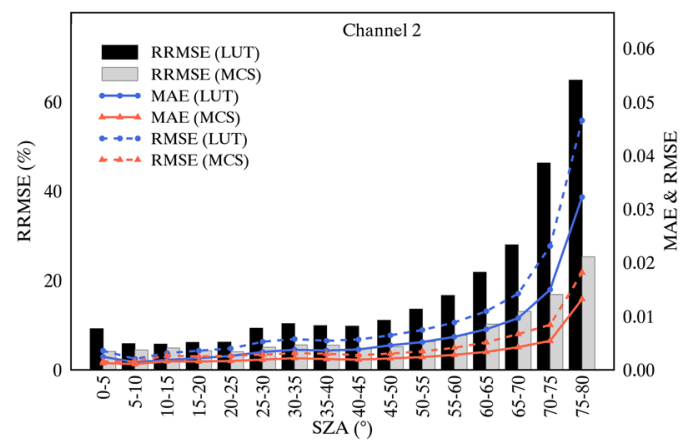

(d)

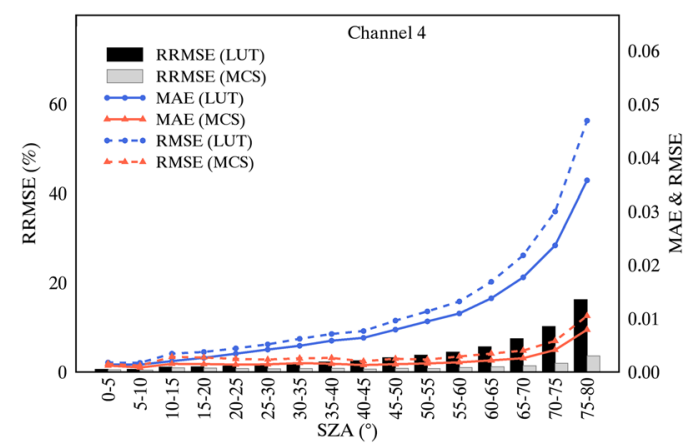

(e)

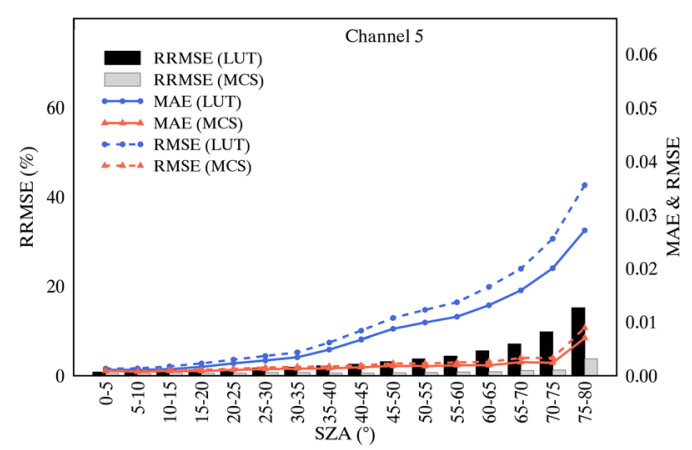

Fig. 5 MAE (solid line), root mean square error (RMSE; dashed line), and relative RMSE (RRMSE; bar) for surface reflectance of each channel according to the SZA interval

et al. 2018); thus, $x a$ of the interpolated 6S LUT differed slightly from $x a$ calculated directly by $6 \mathrm{~S}$. As the condition of RAA changes in all channels, the relative MAE value of $x a$ fluctuates within $0.01 \%$. However, as the AOD condition changes, there is a relatively large error variation $(0.5 \%)$. The reason for this error tendency is that $x a$ is more sensitive to AOD changes than RAA changes.

$x b$ also showed a relative MAE of less than $5 \%$ in all cases and channels, compared to $x b$ calculated directly with $6 \mathrm{~S}$. In all cases, a large relative MAE was observed in channel 5, up to $2.8 \%$ for case 6 . Given the same AOD condition for all channels, a small relative MAE was obtained for RAA equal to $90^{\circ}$ (cases 3 and 4). The relative MAE was $0.18 \%$ in case 4 of channel 1. In the case of $x b$, similar to $x a$, the differences were small for most SZA and VZA conditions; however, the difference increased significantly when SZA and VZA exceeded $75^{\circ}$, up to $-1.143(-16.8 \%)$ in case 6 of channel 5 . In the case of SZA and VZA above $75^{\circ}, x b$ increased sharply with SZA and VZA. Therefore, due to the limitations of MCS interpolation mentioned above, the $x b$ of the interpolated $6 \mathrm{~S}$ LUT differed slightly from $x b$ calculated directly by $6 \mathrm{~S}$ under high VZA and SZA conditions. The relative MAE of $x b$ has variability as the RAA and AOD change. Thus, $x b$ is more sensitive to changes in RAA than $x a$. 
(a)

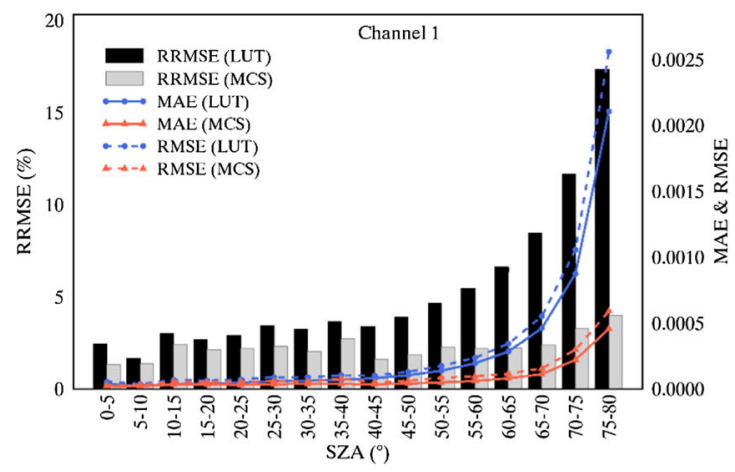

(c)

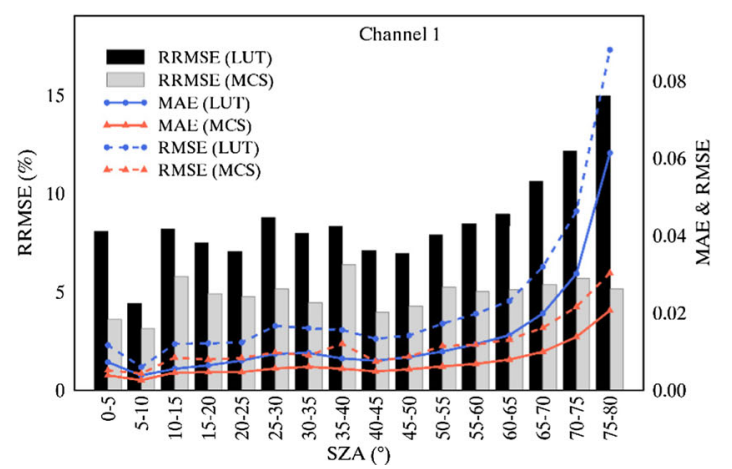

(b)

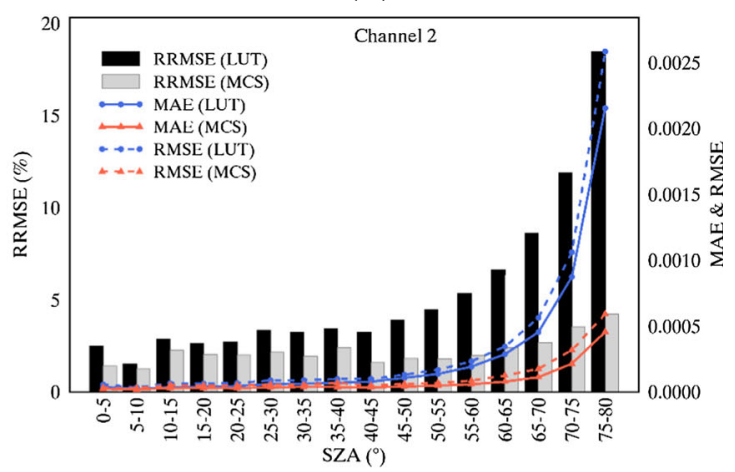

(d)

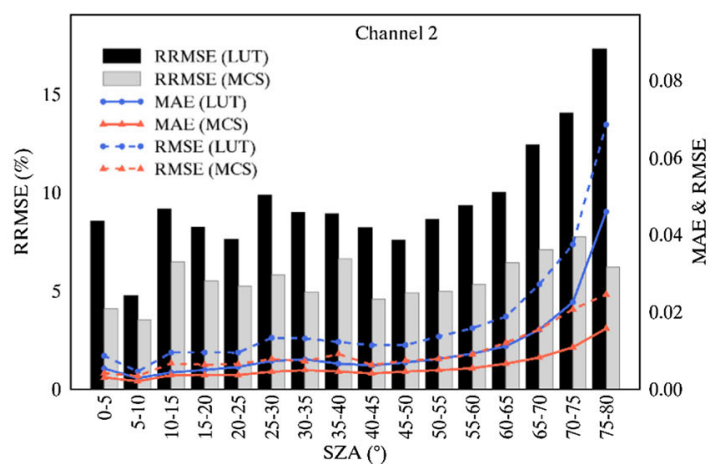

Fig. 6 Same as Fig. 5, but for xa (a-b) and xb (c-d) of channels 1(left) and 2 (right)

\subsection{Evaluation of Accuracy for Surface Reflectance}

Calculating surface reflectance directly with $6 \mathrm{~S}$ can take a long time. Therefore, we quantitatively evaluated the LUT based surface reflectance by sampling pixels corresponding to various SZA and VZA conditions. We sampled about 58,000 pixels per channel for five shortwave channels of the AHI. Figure 4 shows the VZA and SZA distributions of sampled pixels for quantitative evaluation of the surface reflectance. The sampled pixels were relatively uniform in number for all SZAs, with the exception of $\mathrm{SZA}<15^{\circ}$. For the VZA, however, the number of samples was small for VZA $<20^{\circ}$ and $\mathrm{VZA}>55^{\circ}$. AHI is located at $140.7^{\circ}$ above the equator for its Earth's observations. Therefore, in the region corresponding to a low VZA range, there is a small number of land pixels; in the region corresponding to a high VZA range, the land pixel is relatively small. In particular, equatorial regions with low VZA show low sampling numbers due to the large number of pixels contaminated by clouds.

Table 4 shows MAE, RMSE, and RRMSE for TOC reflectance $_{\mathrm{LUT}}$ and TOC reflectance $\mathrm{MCS}_{\mathrm{MC}}$ compared to TOC reflectance6S for all sampled data. The MAE and RMSE of TOC reflectance $_{\text {LUT }}$ range from $0.0031-0.0050$ and from $0.0043-0.0065$, respectively. The MAE and RMSE of TOC reflectance $_{\mathrm{MCS}}$ were $0.0014-0.0026$ and $0.00194-0.0036$, respectively, showing higher accuracy after 6S LUT interpolation of all five channels. The RRMSE of the 6S LUT varied from $2.10 \%$ to $17.51 \%$ before interpolation and from $0.65 \%$ to $9.29 \%$ after interpolation. After interpolation, the RRMSE of all channels improved by approximately two-fold, compared to that before interpolation. The greatest improvement in RRMSE was $7.92 \%$ on channel 1 . Channels 4 and 5 showed very small RRMSE values of less than $1 \%$.

Because surface reflectance is mainly affected by the SZA and VZA, we evaluated the accuracy of surface reflectance calculated using 6S LUT according to the SZA conditions. For this evaluation, the SZA was categorized into 17 classes in $5^{\circ}$ intervals. Figure 5 shows the MAE, RMSE, and RRMSE of TOC reflectance ${ }_{\mathrm{LUT}}$ and TOC reflectance ${ }_{\mathrm{MCS}}$ for five channels, according to the $17 \mathrm{SZA}$ classes. In the case of TOC reflectance $_{\text {LUT }}$, the MAE, RMSE, and RRMSE tended to increase with the SZA for all channels; this increase was particularly sharp for high SZA values, in which SZA $>60^{\circ}$. The RMSE values of channels 1-5 ranged from 0.00264-0.0606, $0.00206-0.0466,0.000138-0.0336,0.00172-0.0469$, and $0.00134-0.0356$, respectively. RRMSE also varied greatly according to the SZA, and increased by $72.6 \%, 64.9 \%, 30.4 \%$, $16.2 \%$, and $15.1 \%$ in the largest SZA class for channels $1-5$, respectively. These findings show that the difference between TOC reflectance LUT $_{\text {IT }}$ and TOC reflectance $_{6 \mathrm{~S}}$ increased with the SZA and showed large differences under high SZA conditions. 
(a)

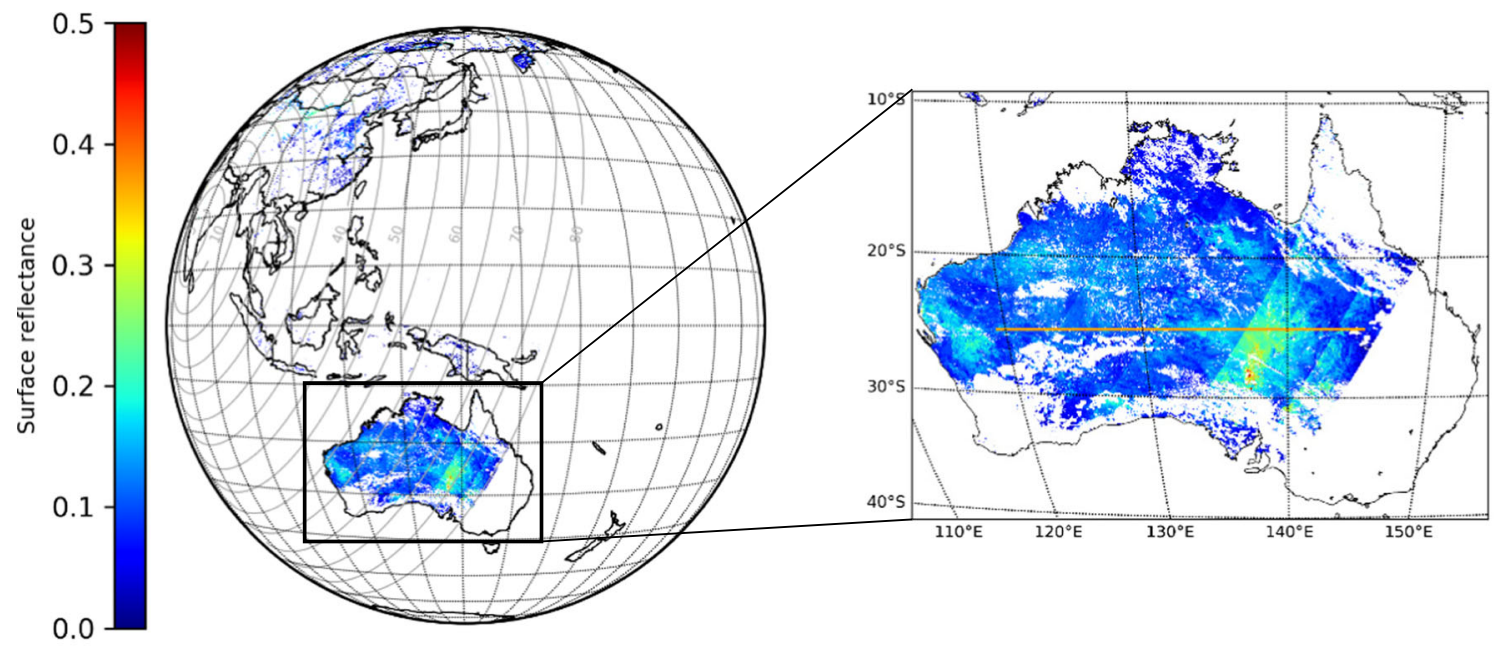

(b)

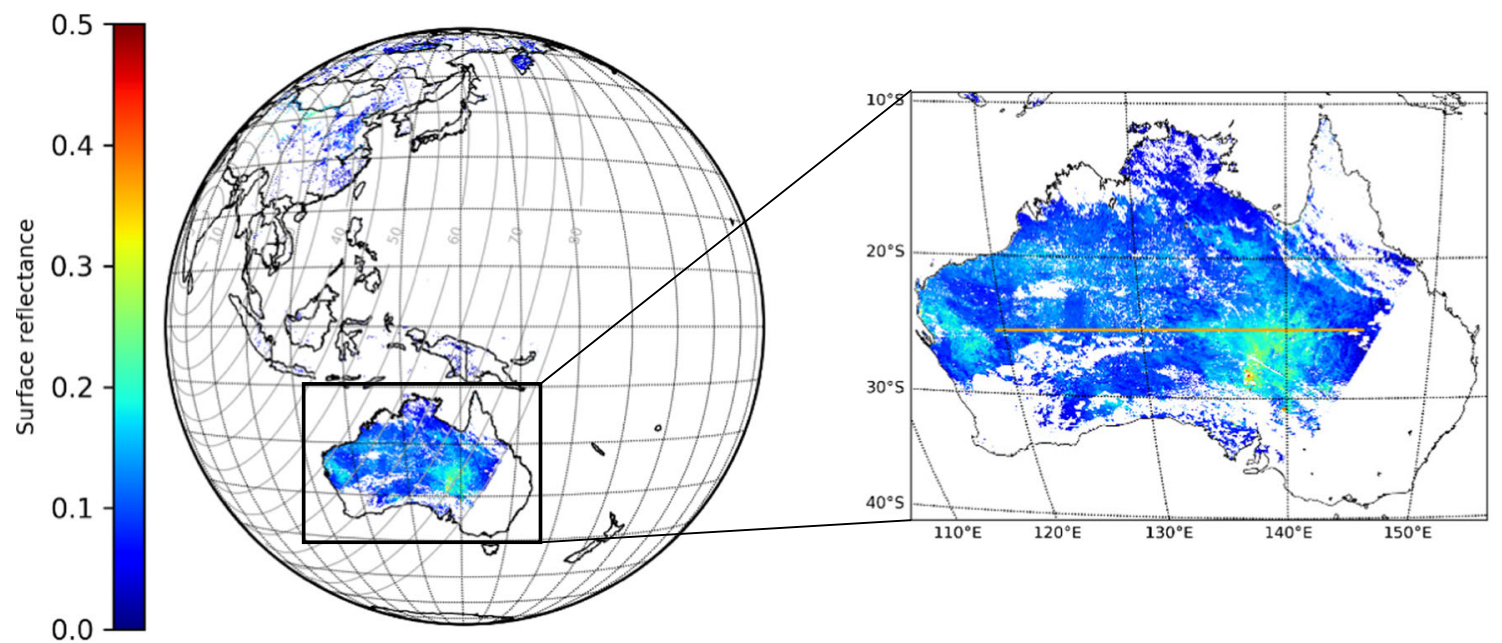

Fig. 7 Spatial distribution of (a) TOC reflectance LUT $_{\text {and }}$ (b) TOC reflectance $_{M C S}$ at channel 3 on August 4, 2017 at 07:00 UTC. The grey solid contour line corresponds to SZA in degree units. TOC reflectanceLUT: top-of-canopy surface reflectance calculated using the

For TOC reflectance ${ }_{\mathrm{MCS}}$, the MAE, RMSE, and RRMSE were lower than those of the TOC reflectance ${ }_{\text {LUT }}$ for all SZA classes and all channels. The MAE, RMSE, and RRMSE also increased with the SZA; however, with the exception of the largest SZA class, there was no significant increase in the error with SZA, unlike that observed for the TOC reflectance LUT $_{\text {. The RMSE }}$ values for the largest SZA class were 0.03, 0.0182, 0.0171, 0.0105 , and 0.0088 , respectively, for channels $1-5$, which are relatively larger than other SZA classes. As mentioned above, when the SZA varies between $75^{\circ}$ and $80^{\circ}$, the atmospheric correction coefficient changes significantly according to the SZA, and a relatively large error occurs when interpolating the 6S LUT with the MCS method. Despite these errors, the TOC non-interpolated 6S LUT; TOC reflectanceMCS: TOC surface reflectance calculated using the interpolated $6 \mathrm{~S}$ LUT, based on the minimum curvature surface method

reflectance $_{\text {MCS }}$ showed a significantly lower RRMSE than the RRMSE of TOCreflectance LUT $_{\text {by }} 45.1 \%, 39.69 \%, 19.8 \%$, $12.6 \%$, and $11.3 \%$, respectively, in the highest SZA class.

The improvement in the accuracy of the surface reflectance was due to the improvement in the $x a$ and $x b$ values, using the 6S LUT interpolation. Figure 6 shows the accuracy indices for $x a$ and $x b$ of channels 1 and 2, according to the SZA class. The accuracy of $x a$ displayed a trend similar to that of TOC reflectance. As the SZA increased, the accuracy decreased; however, the accuracy was much higher after 6S LUT interpolation. In channels 1 and 2, the RRMSE of $x a$ had a low error range of $1.30 \%$ (first SZA class) to $3.99 \%$ (last SZA class) and $1.24 \%$ (second SZA class) to $4.23 \%$ (last SZA class), respectively, 
Fig. 8 Linear profile of surface reflectance for channels (a) 3, (b) 4 , and (c) 5. The red, blue, green circle at the top of each figure indicates TOC reflectance LUT $_{\text {, }}$ TOC reflectance $\mathrm{MCS}_{\mathrm{M}}$, and TOC reflectance $_{6 \mathrm{~S}}$ of each channel, respectively; red and blue triangles at the bottom of each figure indicate the difference between TOC reflectance LUT $_{\text {and }}$ TOC reflectance ${ }_{6 \mathrm{~S}}$, and the difference between TOC reflectance $\mathrm{MCS}_{\mathrm{S}}$ and TOC reflectance $_{6 \mathrm{~S}}$, respectively. TOC reflectance6S: TOC reflectance calculated directly using $6 \mathrm{~S}$ (a)

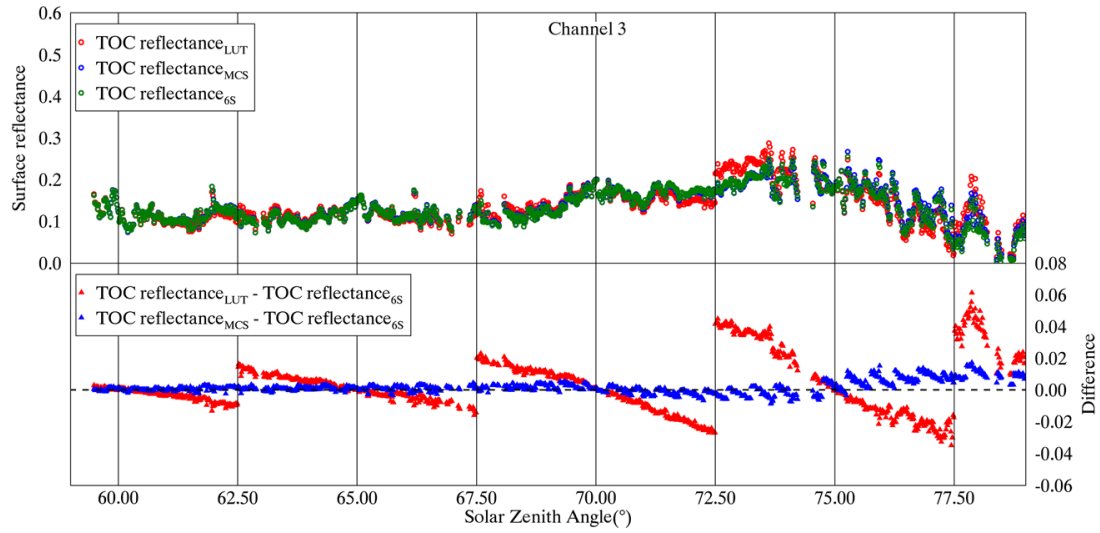

(b)

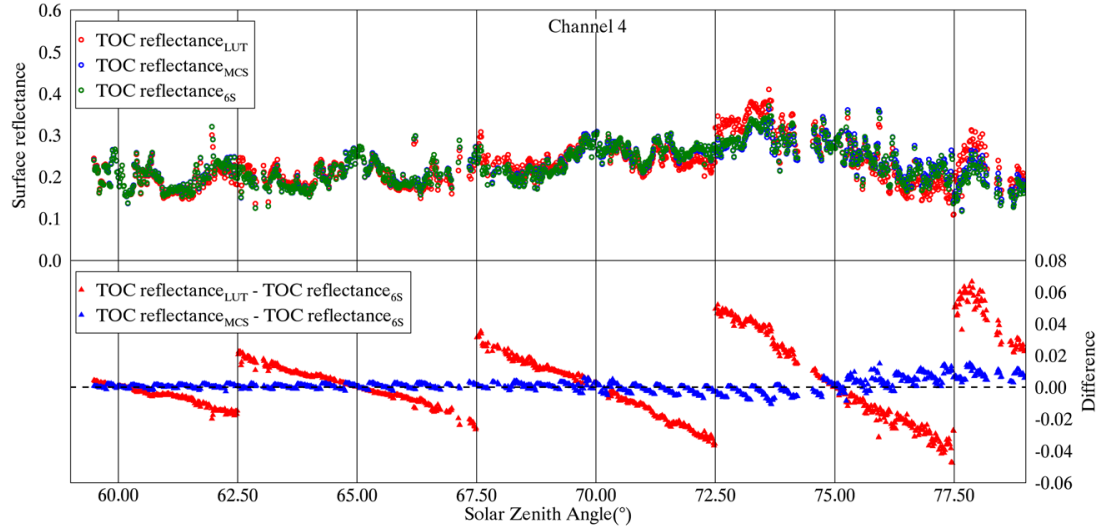

(c)

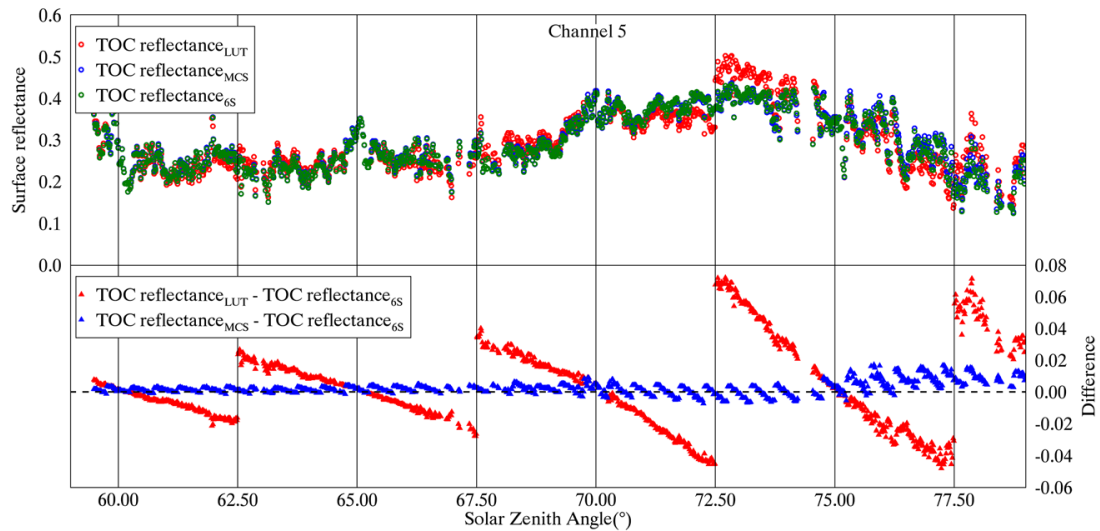

depending on the SZA class. After interpolating the 6S LUT, the accuracy of $x b$ of all SZA classes improved, and the RRMSE decreased by $13.3 \%$ and $14.1 \%$ for channels 1 and 2 respectively, in the last SZA class. However, the improvement in $x b$ was less than that of $x a$. Because $x a$ is more sensitive to the SZA and VZA than other input parameters, it is greatly improved by interpolation of the 6S LUT for SZA and VZA. On the other hand, given that $x b$ is sensitive to both
SZA and VZA, as well as RAA and AOD, the difference in $x b$ can be relatively large, depending on the difference between the LUT construction condition and the actual condition. For this reason, relatively low improvement was achieved in $x b$ than in $x a$. Therefore, the improvement in TOC reflectance by interpolation of the 6S LUT was mainly due to the improvement in $x a$. Similar trends were observed in channels 3-5; however, they were not included for brevity. 
The spatial distribution of the surface reflectance calculated from the Himwari-8/AHI TOA data was analyzed to confirm the improvement with interpolation of the $6 \mathrm{~S}$ LUT. The TOC reflectance LUT $_{\text {T }}$ and TOC reflectance $_{\text {MCS }}$ for channel 3 on August 4, 2017 at 07:00 UTC are shown in Fig. 7. For the TOC reflectance $_{\text {LUT }}$, a discontinuity occurred in the spatial distribution of the surface reflectance in Australia. This is similar to the SZA distribution. The larger the SZA, the larger the difference between neighboring pixels. The discontinuity was clearly visible at higher SZA above $65^{\circ}$, according to the interval of SZA $\left(5^{\circ}\right)$ used for construction of 6S LUT in this study. As mentioned above, the larger the SZA, the greater the change in the atmospheric correction coefficients as the SZA changes. Therefore, this discontinuity appears to be caused by the difference between the LUT construction condition and the sensor observation condition. On the other hand, the TOC reflectance ${ }_{M C S}$ did not show discontinuity in the surface reflectance with SZA variation, particularly for a high SZA. For this reason, there is a difference between the TOC reflectance MCS $_{\text {and TOC reflectance }}$ LUT. Other channels also show the same spatial distribution but are excluded for brevity.

Figure 8 shows the linear profiles of the TOC reflectance LUT, $_{\text {, }}$ TOC reflectance $\mathrm{MCS}_{\mathrm{M}}$, and TOC reflectance ${ }_{6 \mathrm{~S}}$ for channels $3-5$ for the region marked with an orange solid line in Fig. 7, where discontinuity occurs in the spatial distribution of surface reflectance. In Fig. 8, the red, blue, and green circles correspond to TOC reflectance LUT $_{\text {, TOC }}$ reflectance $\mathrm{MCS}_{\mathrm{M}}$, and TOC reflectance $_{6 \mathrm{~S}}$, respectively; red and blue triangles represent the differences between TOC reflectance ${ }_{\mathrm{LUT}}$ and TOC reflectance $_{6 \mathrm{~S}}$ and between TOC reflectance $_{\mathrm{MCS}}$ and TOC reflectance ${ }_{6 \mathrm{~S}}$, respectively. TOC reflectance LUT $_{\text {and TOC reflectance }}$ MCS showed a linear profile similar to $\mathrm{TOC}$ reflectance ${ }_{6 \mathrm{~S}}$ as a whole; however, there was a difference in TOC reflectance LUT $_{\text {as }}$ a the SZA at the time of observation differed considerably from that of the SZA used for LUT construction. When the actual SZA is smaller (larger) than the SZA corresponding to the LUT condition, the difference indicates a positive (negative) value. The magnitude of the difference increased with the SZA; the RRMSE values of channels $3-5$ were $14.16 \%, 11.03 \%$, and $10.06 \%$, respectively, for a SZA above $70^{\circ}$. TOC reflectance MCS $_{\text {s }}$ showed a linear profile similar to the TOC reflectance ${ }_{6 \mathrm{~S}}$ for $\mathrm{SZA} \leq 75^{\circ}$. For a SZA above $75^{\circ}$, TOC reflectance $\mathrm{MCS}_{\mathrm{M}}$ tended to be overestimated compared to the TOC reflectance ${ }_{65}$; however, each channel showed a low MAE of 0.007, 0.006, and 0.007, respectively. In the linear profile of TOC reflectance ${ }_{\mathrm{MCS}}$, the difference between TOC reflectance $_{\mathrm{MCS}}$ and TOC reflectance $_{6 \mathrm{~S}}$ also repeated the positive/negative trend depending on whether the SZA value (interval chosen) corresponded to a small or large SZA; this is an inherent error of the LUT method. However, the difference between TOC reflectance ${ }_{\mathrm{MCS}}$ and $\mathrm{TOC}$ reflectance $_{6 \mathrm{~S}}$ was small.
For the TOC reflectance $\mathrm{MCS}_{\text {with }} \mathrm{SZA}>70^{\circ}$, the RRMSEs of channels 3 , 4 , and 5 were $3.55 \%, 2.01 \%$, and $1.84 \%$, respectively, which improved by $10.16 \%, 9.02 \%$, and $8.22 \%$, respectively, compared to the RRMSE of the same channel before interpolation of the 6S LUT. Similar trends were observed in channels 1 and 2; however, they were not included for brevity.

\section{Concluding Remarks}

We proposed a method for improving the quality of surface reflectance by interpolating the 6S LUT for application to the Himawari-8/ AHI. The interpolated 6S LUT showed lower MAE in all channels compared to the non-interpolated $6 \mathrm{~S}$ LUT. TOC reflectance ${ }_{\mathrm{MCS}}$ more agreed well with TOC reflectance $_{6 \mathrm{~S}}$ in all cases than TOC reflectance ${ }_{\mathrm{LUT}}$. Particularly, for SZA $>75^{\circ}$, an improvement of $45.1 \%, 39.6 \%, 19.8 \%$, $12.57 \%$, and $11.33 \%$ in RRMSE were indicated for channels $1-5$, respectively. Linear profile analyses indicated a slight over-

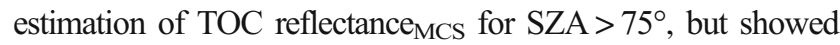
good agreement without discontinuity along 6S LUT interval over the entire SZA range.

The proposed method in this study can improve the accuracy of surface reflectance measurements, even for a high SZA, by constructing a detailed 6S LUT with a short processing time. This can increase the availability of surface reflectance values at high latitudes, where high SZA observations are made. In addition, the proposed method can be applied to next-generation geostationary orbiting satellites, such as GK-2A (South Korea), GOES-R (United States), and Meteosat Third Generation (Europe). In order to apply this method to next-generation geostationary satellites, 6S LUT for each satellite must be built in advance, which takes a long time. However, if the 6S LUT is constructed, the proposed method can be applied without any optimization method and the production of improved surface reflectance can be expected.

In order to improve the accuracy of the calculation of the surface reflectance in future studies, the accuracy of the atmospheric correction coefficient should be ensured for the portion where the value of the atmospheric correction coefficient varies greatly with SZA and VZA. In addition, it is necessary to analyze and improve the error according to the LUT interval of other input variables such as AOD and RAA, which greatly affect $x b$.

Acknowledgements This work was supported by "Development of Scene Analysis \& Surface Algorithms" project, funded by ETRI, which is a subproject of "Development of Geostationary Meteorological Satellite Ground Segment (NMSC-2019-01)" program funded by NMSC (National Meteorological Satellite Center) of KMA(Korea Meteorological Administration).

One of authors (Kyeong-Sang Lee) was supported by the BK21 plus Project of the Graduate School of Earth Environmental Hazard System. 
Open Access This article is licensed under a Creative Commons Attribution 4.0 International License, which permits use, sharing, adaptation, distribution and reproduction in any medium or format, as long as you give appropriate credit to the original author(s) and the source, provide a link to the Creative Commons licence, and indicate if changes were made. The images or other third party material in this article are included in the article's Creative Commons licence, unless indicated otherwise in a credit line to the material. If material is not included in the article's Creative Commons licence and your intended use is not permitted by statutory regulation or exceeds the permitted use, you will need to obtain permission directly from the copyright holder. To view a copy of this licence, visit http://creativecommons.org/licenses/by/4.0/.

\section{References}

Adler-Golden S.M., Matthew M.W., Bernstein L.S., Levine R.Y., Berk A., Richtsmeier S.C., Acharya P.K., Anderson G.P., Felde J.W., Gardner J., Hokeb M., Jeongb L.S., Pukallb B., Mellob J., Ratkowskib A., Burke H.-H.: Atmospheric correction for shortwave spectral imagery based on modtran4. Proc. SPIE 3753, Imaging Spectrometry V, 61-69 (1999). https://doi.org/10.1117/12.366315

Chai, T., Draxler, R.R.: Root mean square error (RMSE) or mean absolute error (MAE)?-arguments against avoiding RMSE in the literature. Geosci. Model Dev. 7, 1247-1250 (2014). https://doi.org/10.5194/ gmd-7-1247-2014

Choi, Y.Y., Suh, M.S.: Development of Himawari-8/Advanced Himawari Imager (AHI) land surface temperature retrieval algorithm. Remote Sens. 10, 2013 (2018). https://doi.org/10.3390/rs10122013

Despotovic, M., Nedic, V., Despotovic, D., Cvetanovic, S.: Evaluation of empirical models for predicting monthly mean horizontal diffuse solar radiation. Renew. Sust. Energ. Rev. 56, 246-260 (2016). https://doi.org/10.1016/j.rser.2015.11.058

Dietz, A., Klein, I., Gessner, U., Frey, C., Kuenzer, C., Dech, S.: Detection of water bodies from AVHRR data - a TIMELINE thematic processor. Remote Sens. 9, 57 (2017). https://doi.org/10.3390/rs9010057

Dorji, P., Fearns, P.: Atmospheric correction of geostationary Himawari-8 satellite data for total suspended sediment mapping: a case study in the coastal waters of Western Australia. ISPRS J. Photogramm. Remote Sens. 144, 81-93 (2018). https://doi.org/10.1016/j. isprsjprs.2018.06.019

Franch, B., Roger J.C., Vermote E.F.: Suomi-NPP VIIRS Surface Reflectance Algorithm Theoretical Basis Document (ATBD). Available at https://viirsland.gsfc.nasa.gov/PDF/ATBD_VIIRS_ SR_v2.pdf. Accessed 10 October 2016

Fraser, R.S., Ferrare, R.A., Kaufman, Y.J., Markham, B.L., Mattoo, S.: Algorithm for atmospheric corrections of aircraft and satellite imagery. Int. J. Remote Sens. 13, 541-557 (1992). https://doi.org/10. 1080/01431169208904056

Gittings, J.A., Raitsos, D.E., Racault, M.F., Brewin, R.J., Pradhan, Y., Sathyendranath, S., Platt, T.: Seasonal phytoplankton blooms in the Gulf of Aden revealed by remote sensing. Remote Sens. Environ. 189, 56-66 (2017). https://doi.org/10.1016/j.rse.2016.10.043

Grgić, M., Varga, M., Bašić, T.: Empirical research of interpolation methods in distortion modeling for the coordinate transformation between local and global geodetic datums. J. Surv. Eng. 142, 05015004 (2015). https://doi.org/10.1061/(ASCE)SU.1943-5428. 0000154

Hadjimitsis, D.G., Papadavid, G., Agapiou, A., Themistocleous, K., Hadjimitsis, M.G., Retalis, A., Michaelides, S., Chrysoulakis, N., Toulios, L., Clayton, C.R.I.: Atmospheric correction for satellite remotely sensed data intended for agricultural applications: impact on vegetation indices. Nat. Hazards Earth Syst. Sci. 10, 89-95 (2010). https://doi.org/10.5194/nhess-10-89-2010
Hilker, T.: Surface reflectance/bidirectional reflectance distribution function. Elsevier (2018)

Jiménez-Muñoz, J.C., Sobrino, J.A., Mattar, C., Franch, B.: Atmospheric correction of optical imagery from MODIS and reanalysis atmospheric products. Remote Sens. Environ. 114, 2195-2210 (2010). https://doi.org/10.1016/j.rse.2010.04.022

Kaufman, Y.J.: Atmospheric effect on spectral signature - measurements. Adv. Space Res. 7, 203-206 (1987). https://doi.org/10.1016/02731177(87)90313-9

Kaven, J.O., Mazzeo, R., Pollard, D.D.: Constraining surface interpolations using elastic plate bending solutions with applications to geologic folding. Math. Geosci. 41, 1-14 (2009). https://doi.org/10. 1007/s11004-008-9201-5

Kotchenova, S.Y., Vermote, E.F., Matarrese, R., Klemm Jr., F.J.: Validation of a vector version of the $6 \mathrm{~S}$ radiative transfer code for atmospheric correction of satellite data. Part I: Path radiance. Appl. Opt. 45(26), 67626774 (2006). https://doi.org/10.1364/AO.45.006762

Kotchenova, S.Y., Vermote, E.F., Levy, R., Lyapustin, A.: Radiative transfer codes for atmospheric correction and aerosol retrieval: intercomparison study. Appl. Opt. 47, 2215-2226 (2008). https://doi. org/10.1364/AO.47.002215

Lee, C.S., Yeom, J.M., Lee, H.L., Kim, J.J., Han, K.S.: Sensitivity analysis of 6S-based look-up table for surface reflectance retrieval. AsiaPac. J. Atmos. Sci. 51, 91-101 (2015). https://doi.org/10.1007/ s13143-015-0062-9

Liang, S., Fang, H., Chen, M.: Atmospheric correction of Landsat ETM+ land surface imagery. I. Methods. IEEE Trans. Geosci. Remote Sens. 39, 2490-2498 (2001). https://doi.org/10.1109/36.964986

Liang, S., Wang D., He T.: GOES-R Advanced Baseline Imager (ABI) Algorithm Theoretical Basis Document for Surface Albedo. NOAA NESDIS CENTER for SATELLITE APPLICATIONS and REARCH, version 1.0 (2010)

Liang, S., Li X., Wang J.: Advanced remote sensing: terrestrial information extraction and applications (Eds.). Elseview Science: Amsterdam, The Netherlands (2012)

Lyapustin, A., Martonchik, J., Wang, Y., Laszlo, I., Korkin, S.: Multiangle implementation of atmospheric correction (MAIAC): 1. Radiative transfer basis and look-up tables. J. Geophys. Res. Atmos. 116(D03210), (2011). https://doi.org/10.1029/ 2010JD014986

Meyer, K., Platnick, S., Arnold, G.T., Holz, R.E., Veglio, P., Yorks, J., Wang, C.: Cirrus cloud optical and microphysical property retrievals from eMAS during SEAC4RS using bi-spectral reflectance measurements within the $1.88 \mu \mathrm{m}$ water vapor absorption band. Atmos. Meas. Tech. 9, 1743 (2016). https://doi.org/10.5194/amt-9-1743-2016

Nefeslioglu, H.A., San, B.T., Gokceoglu, C., Duman, T.Y.: An assessment on the use of Terra ASTER L3A data in landslide susceptibility mapping. Int. J. Appl. Earth Obs. Geoinf. 14, 40-60 (2012). https:// doi.org/10.1016/j.jag.2011.08.005

NMSC: GK-2A AMI Algorithm Theoretical Basis Document. Available at http://nmsc.kma.go.kr/homepage/html/base $/ \mathrm{cmm} / \mathrm{selectPage.do?}$ page=static.edu.atbdGk2a. Accessed 15 April 2019

Nunes, A.S.L., Marcal, A.R.S., Vaughan, R.A.: Fast over-land atmospheric correction of visible and near-infrared satellite images. Int. J. Remote Sens. 29, 3523-3531 (2008). https://doi.org/10.1080/ 01431160701592445

Patenaude, G., Hill, R.A., Milne, R., Gaveau, D.L.A., Briggs, B.B.J., Dawson, T.P.: Quantifying forest above ground carbon content using LiDAR remote sensing. Remote Sens. Environ. 93, 368-380 (2004). https://doi.org/10.1016/j.rse.2004.07.016

Proud, S.R., Rasmussen, M.O., Fensholt, R., Sandholt, I., Shisanya, C., Mutero, W., Mbow, C., Anyamba, A.: Improving the SMAC atmospheric correction code by analysis of Meteosat second generation NDVI and surface reflectance data. Remote Sens. Environ. 114, 1687-1698 (2010). https://doi.org/10.1016/j.rse.2010.02.020 
Qu, Y., Liu, Q., Liang, S., Wang, L., Liu, N., Liu, S.: Direct-estimation algorithm for mapping daily land-surface broadband albedo from MODIS data. IEEE Trans. Geosci. Remote Sens. 52, 907-919 (2014). https://doi.org/10.1109/TGRS.2013.2245670

Rabah, M., Kaloop, M.: The use of minimum curvature surface technique in geoid computation processing of Egypt. Arab. J. Geosci. 6, 1263 1272 (2013). https://doi.org/10.1007/s12517-011-0418-0

Ruddick, K., Neukermans, G., Vanhellemont, Q., Jolivet, D.: Challenges and opportunities for geostationary ocean colour remote sensing of regional seas: a review of recent results. Remote Sens. Environ. 146, 63-76 (2014). https://doi.org/10.1016/j.rse.2013.07.039

Rufo, M., Antolín, A., Paniagua, J.M., Jiménez, A.: Optimization and comparison of three spatial interpolation methods for electromagnetic levels in the AM band within an urban area. Environ. Res. 162, 219-225 (2018). https://doi.org/10.1016/j.envres.2018.01.014

Smith, W.H.F., Wessel, P.: Gridding with continuous curvature splines in tension. Geophysics. 55, 293-305 (1990). https://doi.org/10.1190/1. 1442837

Vermote, E.F., Tanré, D., Deuze, J.L., Herman, M., Morcette, J.J.: Second simulation of the satellite signal in the solar spectrum, 6S: an overview. IEEE Trans. Geosci. Remote Sens. 35, 675-686 (1997). https://doi.org/10.1109/36.581987

Vermote, E. F., Tanré D., Deuzé J. L., Herman M., Morcrette J. J., Kotchenova S. Y.: Second simulation of a satellite signal in the solar spectrum-vector (6SV). 6S User Guide Version, 3, 1-55 (2006)

Willmott, C.J., Matsuura, K.: Advantages of the mean absolute error (MAE) over the root mean square error (RMSE) in assessing average model performance. Clim. Res. 30, 79-82 (2005). https://doi. org $/ 10.3354 / \mathrm{cr} 030079$

Wu, X., Wen, J., Xiao, Q., Yu, Y., You, D., Hueni, A.: Assessment of NPP VIIRS albedo over heterogeneous crop land in northern China. J.
Geophys. Res. Atmos. 122, 13138-13154 (2017). https://doi.org/ 10.1002/2017JD027262

Yeom, J.M., Ko, J., Hwang, J., Lee, C.S., Choi, C.U., Jeong, S.: Updating absolute radiometric characteristics for KOMPSAT-3 and KOMPSAT-3A multispectral imaging sensors using wellcharacterized pseudo-invariant tarps and microtops II. Remote Sens. 10, 697 (2018). https://doi.org/10.3390/rs10050697

Yumimoto, K., Nagao, T.M., Kikuchi, M., Sekiyama, T.T., Murakami, H., Tanaka, T.Y., Ogi, A., Irie, H., Kharti, P., Okumura, H., Arai, K., Morino, I., Uchino, O., Maki, T.: Aerosol data assimilation using data from Himawari-8, a next-generation geostationary meteorological satellite. Geophys. Res. Lett. 43, 5886-5894 (2016). https://doi. org/10.1002/2016GL069298

Zhang, H., Kondragunta, S., Laszlo, I., Liu, H., Remer, L.A., Huang, J., Superczynski, S., Ciren, P.: An enhanced VIIRS aerosol optical thickness (AOT) retrieval algorithm over land using a global surface reflectance ratio database. J. Geophys. Res. Atmos. 121, 10-717 (2016). https://doi.org/10.1002/2016JD024859

Zhao, W., Tamura, M., Takahashi, H.: Atmospheric and spectral corrections for estimating surface albedo from satellite data using $6 \mathrm{~S}$ code. Remote Sens. Environ. 76, 202-212 (2001). https://doi.org/10. 1016/S0034-4257(00)00204-2

Zhou, J., Wang, J., Li, J., Hu, D.: Atmospheric correction of PROBA/ CHRIS data in an urban environment. Int. J. Remote Sens. 32(9), 2591-2604 (2011). https://doi.org/10.1080/01431161003698443

Publisher's Note Springer Nature remains neutral with regard to jurisdictional claims in published maps and institutional affiliations. 